\title{
ASPECTOS GEOQUÍMICOS DAS ROCHAS GRANITÓIDES DA SUÍTE INTRUSIVA PEDRA PINTADA, NORTE DO ESTADO DE RORAIMA
}

\author{
LEDA M. B. FRAGA ${ }^{1}$; REGINA C. HADDAD ${ }^{2}$ \& NELSON J. REIS ${ }^{1}$
}

\begin{abstract}
GEOCHEMICAL ASPECTS OF THE PEDRA PINTADA SUITE GRANITOIDS, RORAIMA STATE, BRAZIL Late to pos- Transamazonian granitoids from the Pedra Pintada Suite (PPS) crop out along an E-W trending belt at the northern part of Roraima state, limited by narrow shear zones. The PPS consiste of hornblende-biotite granodiorite with subordinate tonalites and monzodiorites (GND); biotite-monzogranites, with minor granodiorites (MZG); leuco to hololeucocratic monzogranites (MGL) and leucocratic syenogranite (SNG). These granitoids are metaluminous to weakly peraluminous and show calc-alkaline character. For the same silica range, the GND and MGL exhibit lower $\mathrm{TiO}_{2}$ contents than the MZG and SNG. Relative to the MZG, MGL and SNG, the GND is characterised by higher $\mathrm{Sr}$ and lower $\mathrm{Rb}, \mathrm{Zr}$ and $\mathrm{Y}$ concentrations. The MZG shows the higher REE contents among the PPS granitoids. REE patterns exhibit moderate to pronounced negative Eu anomalias, and multielementar diagrams demonstrate an enrichment in LIL relative to HFS elements. These chemical characteristics are similar to that observed in calc-alkaline granitoids from modern ares, or collision belts, characterised by subduction signatures. The geochemical and geological aspects of the PPS granitoids may be correlated to a pos-collisional setting related to the Transamazonian cycle.
\end{abstract}

Keywords: granitoids, calc-alkaline magmatism, whole-rock chemistry, Guyana Shield, Roraima State

RESUMO A Suíte Intrusiva Pedra Pintada (SIPP) aflora em faixa E-W, limitada por zonas de cisalhamento, no norte do Estado de Roraima, Escudo das Guianas, representando um magmatismo tardi- a pós-Transamazônico. Os granitóides da suíte foram agrupados em quatro conjuntos distintos, em funcão de suas características composicionais dominantes: (hornblenda)-biotita granodioritos com restritos termos tonalíticos e quartzo monzodioríticos (GND); biotita monzogranitos com variações para granodioritos (MZG); biotita monzogranitos leuco a hololeucocráticos (MGL); e sienogranitos leucocráticos (SNG). Geoquimicamente os granitóides Pedra Pintada são cálcio-alcalinos, metaluminosos a fracamente peraluminosos, com grupos químicos distintos representados, principalmente, pelo menor conteúdo de TiCh do conjunto dos GND e MGL em relação aos MZG e SNG. Teores relativamente mais baixos em $\mathrm{Rb}, \mathrm{Zr}$ e $\mathrm{Y}$ e mais elevados em $\mathrm{Sr}$ caracterizam os GND, enquanto proporções maiores de terras raras totais distinguem os MZG dos demais granitóides. Padrões de ETR geralmente fracionados, com anomalias negativas de Eu pronunciadas a ausentes caracterizam os diferentes grupos químicos, além de concentrações relativamente elevadas de elementos LIL (K, Rb, Ba, TRL) em relação aos elementos HFS (Nb, Ti). As feições geoquímicas da SIPP são similares às de granitóides de arcos magmáticos modernos ou de ambientes pós-colisionais, envolvendo contribuicões de fontes mantélicas com assinatura de subducção e a participação de componentes de manto intraplaca e/ou material crustal. Suas características químicas e seu posicionamento temporal (em torno de $2,0 \mathrm{Ga}$ ) são compatíveis com geração em ambiente pós-colisional relacionado ao Ciclo Transamazônico, interpretado no Escudo das Guianas como resultante da evolução de arcos magmáticos envolvendo um regime de subducção de crosta oceânica e acreção crustal, seguido de um estágio colisional.

Palavras-chaves: granitóides, magmatismo cálcio-alcalino, litogeoquímica, Escudo das Guianas, Estado de Roraima

INTRODUÇÃO O magmatismo granitóide que caracteriza a porção brasileira do Escudo das Guianas está representado por diversas suítes intrusivas, associadas ou não a manifestações vulcânicas, que apresentam feições geoquímicas peculiares e registram uma complexa evolução tectonomagmática desde o final do Proterozóico Inferior até o Proterozóico Médio (e.g. Dall'Agnol et al 1987, 1994). Em Roraima, vários autores mencionaram a presença de corpos granitóides com características químicas e/ou petrográficas distintas, relacionados ao final do Ciclo Transamazônico (e.g. Araújo Neto \& Moreira 1976 - Suíte Água Branca; Melo et al. 1978 - Granito Viaquário), ou interpretados como pertencentes ao embasamento, de idade arqueana (Melo et al. 1978 - Complexo Maracá). Dados recentes (e.g. Fraga et al. 1996; Oliveira et al. 1996a, b) têm permitido a individualização de associações que refletem um magmatismo cálcioalcalino, tardi- a pós-tectônico (suítes Pedra Pintada e Água Branca), e uma granitogênese anorogênica, de afinidade alcalina (suítes Saracura e Mapuera, Mucajaí e Abonari - Reis \& Fraga 1995; Fraga \& Reis 1995; Dados inéditos do Projeto Caracaraí -CPRM/Manaus). A reavaliação petrográfica do acervo de lâminas delgadas utilizado por Melo et al (1978) para definir a unidade Granito Viaquário revelou a incon- sistência da mesma, pois inclui inúmeros granitóides com fluorita relacionados à Suíte Intrusiva Saracura, o que levou Fraga et al. (1996) a descartar a designação Viaquário para as rochas graníticas do norte de Roraima. E digno de nota que na localidade tipo - Serra Viaquário - afloram granitos da Suíte Intrusiva Saracura (S. da S. Pinheiro, inf. verbal). A denominação Complexo Maracá, há muito abandonada no Estado foi, da mesma forma, descartada pêlos autores. O termo Pedra Pintada refere-se à localidade homónima, situada na margem esquerda do rio Parimé, aproximadamente $140 \mathrm{Km}$ a norte da cidade de Boa Vista, e deriva de belos exemplos de pinturas rupestres.

A Suíte Intrusiva Pedra Pintada (SIPP) reúne rochas de composição dominantemente granodiorítica a granítica, geralmente pouco deformadas, que mantêm contatos tectônicos com os vulcanitos ácidos a intermediários do Grupo Surumu e granitóides da Suíte Intrusiva Saracura (relacionados por Melo et al. (1978) ao vulcano-plutonismo Uatumã), bem como com as litologias supracrustais do Grupo Cauarane. Os dados geocronológicos disponíveis indicam um posicionamento pré-Uatumã para os granitóides da SIPP, tendo sido obtida uma idade de $2.005 \pm 45$ Ma pelo método $\mathrm{Pb} / \mathrm{Pb}$ em zircão (Almeida et al. 1997). As características químicas e

* Companhia de Pesquisas de Recursos Minerais - CPRM/ Manaus - Av. André Araújo n 2160 - Aleixo - CEP 69060-001 - Manaus - AM. - Fax: (092) 663-5531 e-mail: geremi@internext.com.br

** Departamento de Geociências, Instituto de Ciências Exatas, Universidade do Amazonas. Av. Gal. Rodrigo O. J. Ramos, 3000 - Campus Universitário - CEP 69.077-000 - Manaus - AM. - Fax: (092) 644-1510/ 644-2227 
petrográficas da SIPP são similares às da Suíte Intrusiva Água Branca (Araújo Neto \& Moreira 1976; Veiga Jr. et al. 1979; Jorge João et al. 1985; Oliveira et al. 1996a, b), cuja idade $\mathrm{Pb} / \mathrm{Pb}$ em zircão de $1.960 \pm 21$ Ma (Almeida et al. 1997) mostrou-se compatível com a idade isocrônica $\mathrm{Rb} / \mathrm{Sr}$ de 1.910 \pm 47 Ma de Jorge João et al. (1985), e com a isócrona de referência de 1.951 Ma obtida por Santos \& Reis Neto (1982). Por outro lado, a idade U/Pb em zircão de $1.966 \pm 9 \mathrm{Ma}$ (Schobbenhaus et al. 1994), obtida para as rochas vulcânicas do Grupo Surumu na área estudada, se aproxima dos valores encontrados para os granitóides Pedra Pintada e Água Branca, registrando que parte das rochas vulcânicas do norte de Roraima apresentam, da mesma forma que os granitóides, um posicionamento pré-Uatumã.

$\mathrm{O}$ presente artigo reúne os dados obtidos a partir do mapeamento geológico na escala 1:500.000 realizado pelo Programa de Mapeamentos Geológicos Básicos da Companhia de Pesquisa de Recursos Minerais (CPRM/Manaus), e visa a caracterização petrográfica e geoquímica dos granitóides da SIPP, bem como a discussão, ainda que preliminar, da sua evolução e ambiente tectônico.
GEOLOGIA E PETROGRAFIA Aspectos geológicos A SIPP é constituída por granitóides acinzentados, equigranulares médios a grossos, isótropos a levemente foliados, com tipos porfiríticos subordinados, que afloram em uma faixa contínua, aproximadamente $\mathrm{E}-\mathrm{W}$, na porção norte do Estado de Roraima (Fig. 1). Seu posicionamento tardi- a pós-Transamazônico é sugerido pela ausência da petrotrama relacionada ao metamorfismo transamazônico (fácies anfibolito a granulito), e sua colocação é interpretada como posterior à deformação e metamorfismo das rochas supracrustais do Grupo Cauarane, conforme sugerido pela ocorrência localizada de xenólitos de paragnaisses finos e laminados desta unidade nos granitóides da SIPP.

Apesar das limitações impostas pela escala regional do mapeamento, alguns afloramentos permitiram a observação de contatos tectônicos entre a SIPP e os granitos da Suíte Intrusiva Saracura, os vulcanitos do Grupo Surumu e os paragnaisses do Grupo Cauarane. Tais contatos são marcados pelo desenvolvimento de milonitos, em zonas de cisalhamento dúctil relacionadas ao Evento K'Mudku (-1,2 Ga) (Fraga et al 1994) (Fig. 1).

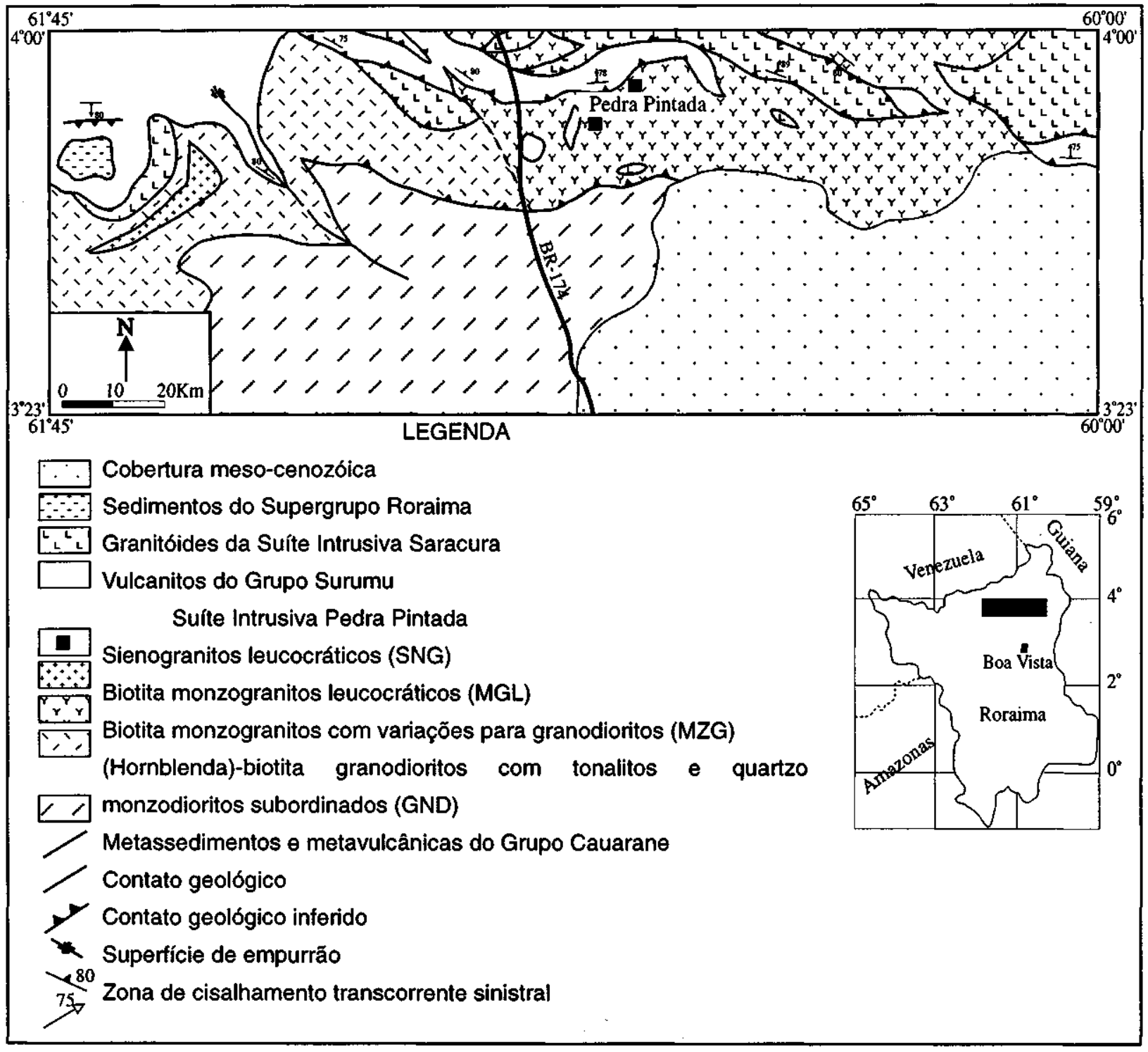

Figura 1 - Mapa geológico simplificado da distribuição da Suite Intrusiva Pedra Pintada, norte do Estado de Roraima. Figure 1 - Geological sketch map illustrating the distribution of the Pedra Pintada Intrusive Suite in the northern Roraima State, Brazil. 
Os granitóides da SIPP foram individualizados em quatro conjuntos distintos, em função de suas características petrográficas e químicas dominantes, bem como sua distribuição no campo. Os dois conjuntos predominantes incluem (hornblenda)-biotita granodioritos com restritos termos tonalíticos, quartzo monzoníticos e quartzo monzodioríticos (GND), com índice de cor (IC) entre 10 e 15, e biotita monzogranitos com variações para granodioritos e tonalitos (MZG), com IC em torno de 10. Biotita monzogranitos leuco a hololeucocráticos

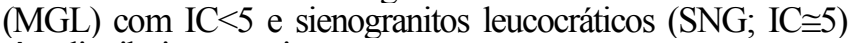
têm distribuição restrita.

Os contatos entre os conjuntos individualizados não foram observados durante os trabalhos de campo. No entanto, a não identificação de tipos petrográficos com características intermediárias entre os diferentes grupos sugere a presença de contatos abruptos. Os GND afloram na porção oeste da região mapeada, enquanto os MZG dominam na sua metade oriental. Os MGL ocorrem em um corpo lenticular próximo ao limite ocidental da área, em meio aos GND, enquanto os SNG constituem ocorrências pontuais na área de domínio dos MZG(Fig. 1).

Enclaves máficos de granulação fina, com formas arredondadas a elipsoidais, em geral centimétricos, são comuns nos granitóides da SIPP, e apresentam contatos nítidos com a rocha encaixante; podem mostrar uma orientação preferencial de caráter não tectônico. Apresentam composição quartzo diorítica a quartzo monzonítica, índice de cor superior a 20 , com os minerais máficos representados essencialmente por biotita e hornblenda. Localmente podem englobar megacristais de feldspato, sugerindo a cristalização contemporânea dos magmas máficos geradores dos enclaves e dos magmas graníticos encaixantes (Vernon et al 1988). Diques dioríticos e veios quartzo-feldspáticos ocorrem localmente e são claramente intrusivos nos granitóides Pedra Pintada.

Petrografia Os granitóides da suíte apresentam, em geral, texturas magmáticas bem preservadas, dispostas numa trama hipidiomórfica granular, com granulação média a grossa. São constituídos essencialmente por plagioclásio, feldspato alcalino, quartzo e biotita; hornblenda é restrita ao conjunto dos GND. Os acessórios comuns são minerais opacos, titanita, apatita e zircão; allanita pode ocorrer nos MZG. Sericita, clorita e epidoto são os minerais secundários mais frequentes, e muscovita derivada do feldspato e da biotita é comum em amostras mais deformadas, nas proximidades do contato com os paragnaisses do Grupo Cauarane.

O plagioclásio, de composição relativamente cálcica (andesina), ocorre em cristais subidiomórficos, por vezes zonados, geralmente sericitizados e saussuritizados; pode mostrar intercrescimento antipertítico, e mirmequita no contato com cristais de feldspato alcalino. Nos MZG são frequentes cristais de plagioclásio envolvidos por manto de microclínio pertítico, o qual pode, localmente, substituir quase totalmente o plagioclásio original. $\mathrm{O}$ feldspato alcalino é o microclínio pertítico, em cristais subidiomórficos a xenomórficos bem desenvolvidos ou em grãos menores intersticiais. Raros cristais subidiomórficos com geminação Carlsbad (ortoclásio) podem ocorrer nos tonalitos dos GND. Nas amostras mais deformadas o intercrescimento pertítico é mais abundante, na forma de lentes em várias direções e veios irregulares, evidenciando uma fase tardia. O quartzo é xenomórfico, intersticial, geralmente fraturado e com forte extinção ondulante; localmente encontra-se em agregados recristalizados. A biotita é o principal mineral máfico, com pleocroísmo verde a castanho esverdeado ou castanho claro, e ocorre em lamelas subidiomórficas a xenomórficas, geralmente em agregados aos quais se associam epidoto, minerais opacos e titanita. Hornblenda verde a castanho esverdeada, subidiomórfica, ocorre nos agregados máficos e mostra, com frequência, transformação para biotita em reações que são acompanhadas por epidoto e minerais opacos. A titanita, em cristais idiomórficos a subidiomórficos, associa-se aos agregados máficos e inclui minerais opacos e zircão, e é mais abundante nos GND. Allanita marrom alaranjada ou avermelhada, subidiomórfica e zonada, com inclusões de minerais opacos e, eventualmente, finas bordas de epidoto, ocorre nos MZG.

Tipos porfiríticos, com fenocristais de feldspato de até 1 $\mathrm{cm}$ em matriz fina, ocorrem pontualmente tanto na área de domínio dos GND quanto dos MZG, correspondendo provavelmente a variedades subvulcânicas. Apresentam fenocristais de plagioclásio zonado (localmente substituídos, em parte, por microclínio pertítico), de quartzo subidiomórfico, por vezes embainhado evidenciando processos corrosivos e, mais raramente, de feldspato alcalino pertítico e biotita, numa matriz dominada por quartzo e plagioclásio nos granodioritos, e quartzo e feldspato alcalino nos monzogranitos. A biotita é o mineral máfico principal, à qual se associam minerais opacos, titanita, apatita e, ocasionalmente, hornblenda.

Os MGL se distinguem dos GND e dos MZG pelo menor conteúdo em minerais máficos, pelo tipo de plagioclásio e pela ausência de titanita entre os minerais acessórios. $\mathrm{O}$ plagioclásio, geralmente sericitizado, não mostra zoneamento e apresenta composição no intervalo do oligoclásio. A biotita, marrom avermelhada a castanha clara, encontra-se em grande parte cloritizada e com muitas inclusões de epidoto. Minerais opacos, apatita, zircão e rara allanita constituem os acessórios.

Os SNG são mineralógica e texturalmente muito similares aos MGL. O feldspato alcalino, invariavelmente pertítico, se distingue pela geminação em grade bem definida, enquanto o plagioclásio pode apresentar sericitização muito pronunciada, levando ao desenvolvimento de lamelas de muscovita que, eventualmente, podem ocupar quase totalmente o grão. $\mathrm{O}$ mineral máfico principal é a biotita, esverdeada a castanha clara, em parte cloritizada, e geralmente associada a cristais bem desenvolvidos de epidoto. $\mathrm{O}$ acessório mais frequente, ao lado dos minerais opacos, é a titanita e, mais raramente, ocorrem apatita e zircão.

LITOGEOQUÍMICA Vinte e seis amostras da SIPP foram analisadas para óxidos maiores e menores, das quais vinte e três foram selecionadas para a dosagem de alguns elementos traços e dezessete para análises de elementos terras raras. Este total inclui uma amostra de enclave máfico (EM), 10 dos GND, 10 dos MZG, 3 dos MGL e 2 dos SNG. Os resultados analíticos de amostras representativas são apresentados na Tabela 1 .

As análises químicas foram realizadas pela GEOSOL Geologia e Sondagens Ltda, Belo Horizonte. Os óxidos de $\mathrm{Si}$, $\mathrm{Ti}, \mathrm{Al}, \mathrm{Fe}^{\mathrm{l}}, \mathrm{Mn}, \mathrm{Mg}, \mathrm{Ca}, \mathrm{K}$ e $\mathrm{P}$, assim como Rb, Ba, Sr, Nb, $\mathrm{Zr}$, Y e Th foram dosados por fluorescência de Raios-X, Na por absorção atómica e $\mathrm{Fe}^{2+}$ por titulação com $\mathrm{KMnO}_{4}$. Os elementos terras raras foram determinados por ICP. Os métodos analíticos e os erros esperados nas determinações são discutidos por Dutra \& Gomes (1984) e Trescases (1984).

Apresentação dos resultados $\mathrm{O}$ comportamento dos elementos maiores, menores e traços define grupos químicos distintos que refletem os conjuntos petrográficos identificados na SIPP. Os GND apresentam razões $\mathrm{Na}_{2} \mathrm{O} / \mathrm{K}_{2} \mathrm{O}$, em geral, maiores que 1 e mg\# entre 33 e 41 , enquanto os MZG se caracterizam por razões $\mathrm{Na}_{2} \mathrm{O} / \mathrm{K}_{2} \mathrm{O}$ menores que 1 (exceto a amostra LM-51B) e valores de mg\# de 24 a 39. Os MGL e SNG correspondem aos conjuntos mais diferenciados da sequência, e mostram razões Na2O/K2O, em geral, menores que 1 e valores de mg\# variando, respectivamente, de 16 a 20 e de 19 a 29 (Tab. 1). As tendências de 

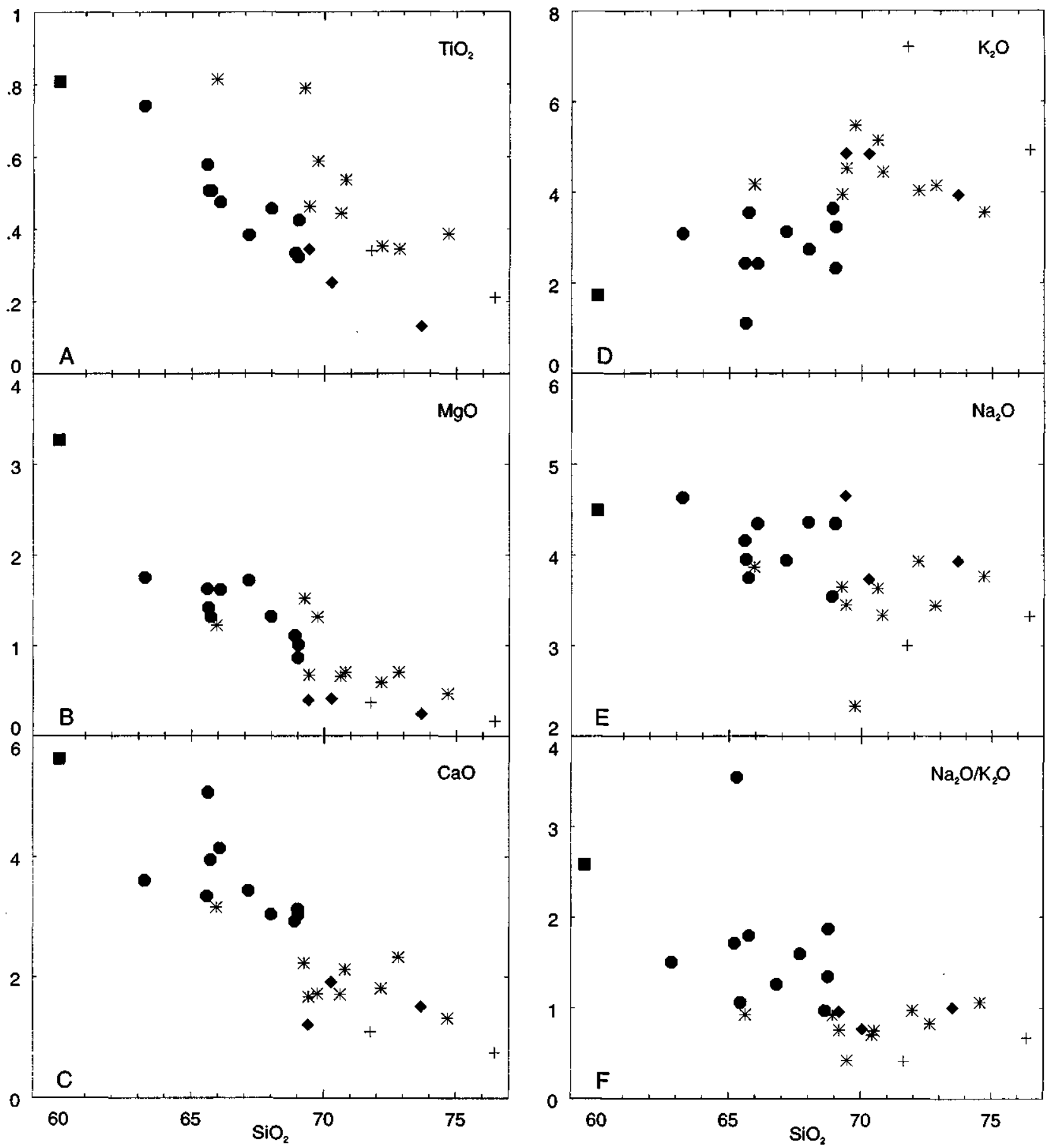

Figura 2 - Diagramas de Harkerdos granitóides da Suite Pedra Pintada. Símbolos: círculos = GND; asteriscos = MZG; losangos $=M G L ;$ cruzes $=S N G ;$ quadrado = enclave máfico.

Figure 2 - Harker diagrams for granitoids of the Pedra Pintada Suite. Symbols: circles = GND; asterisks = MZG; diamonds = MGL; cresses $=$ SNG; $s q u a r e=$ mafic enclave.

variação da maioria dos óxidos maiores e menores são refletidas no aumento da $\mathrm{SiO}_{2}$, e grupos químicos distintos também são caracterizados pelo comportamento de Ti, Rb, Sr, Zr e Y (Figs.2 e 3).

Os MZG e os SNG definem uma sequência de mais alto $\mathrm{TiO}_{2}$ em relação aos GND e MGL (Fig. 2A), estabelecendose duas tendências evolutivas paralelas, que são sugestivas da participação de magmas parentais ligeiramente distintos na evolução dos granitóides da SIPP. Comparativamente os GND são caracterizados por leve enriquecimento em $\mathrm{MgO}$ e $\mathrm{CaO}$ e forte empobrecimento em $\mathrm{K}_{2} \mathrm{O}$ (Fig. 2B, C e D), ao lado de teores mais baixos de $\mathrm{Rb}$ e elevados de $\mathrm{Sr}$ em relação aos demais granitóides (Fig. 3A e B). Os MZG apresentam teores mais elevados em $\mathrm{Rb}, \mathrm{Zr}$ e Y (Fig. 3A, C e D), enquanto proporções reduzidas de $\mathrm{MgO}$ e $\mathrm{CaO}$ distinguem os granitóides mais evoluídos (MGL e SNG, Fig. 2B e C). 


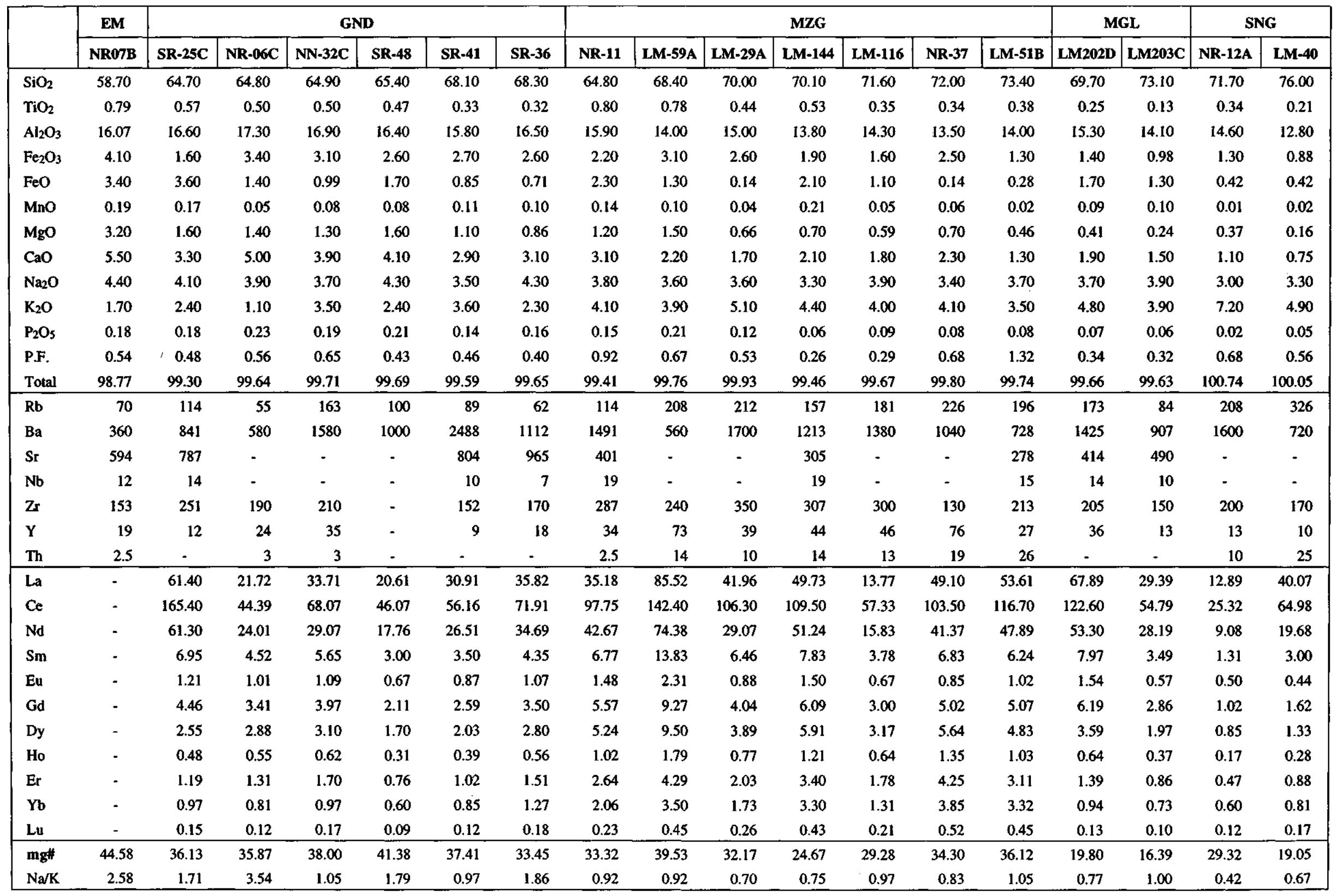

$\mathbf{m g} \#=100 * \mathrm{Mg} /(\mathrm{Mg}+\mathrm{Fe} 2+)$ em proporções catiônicas. 

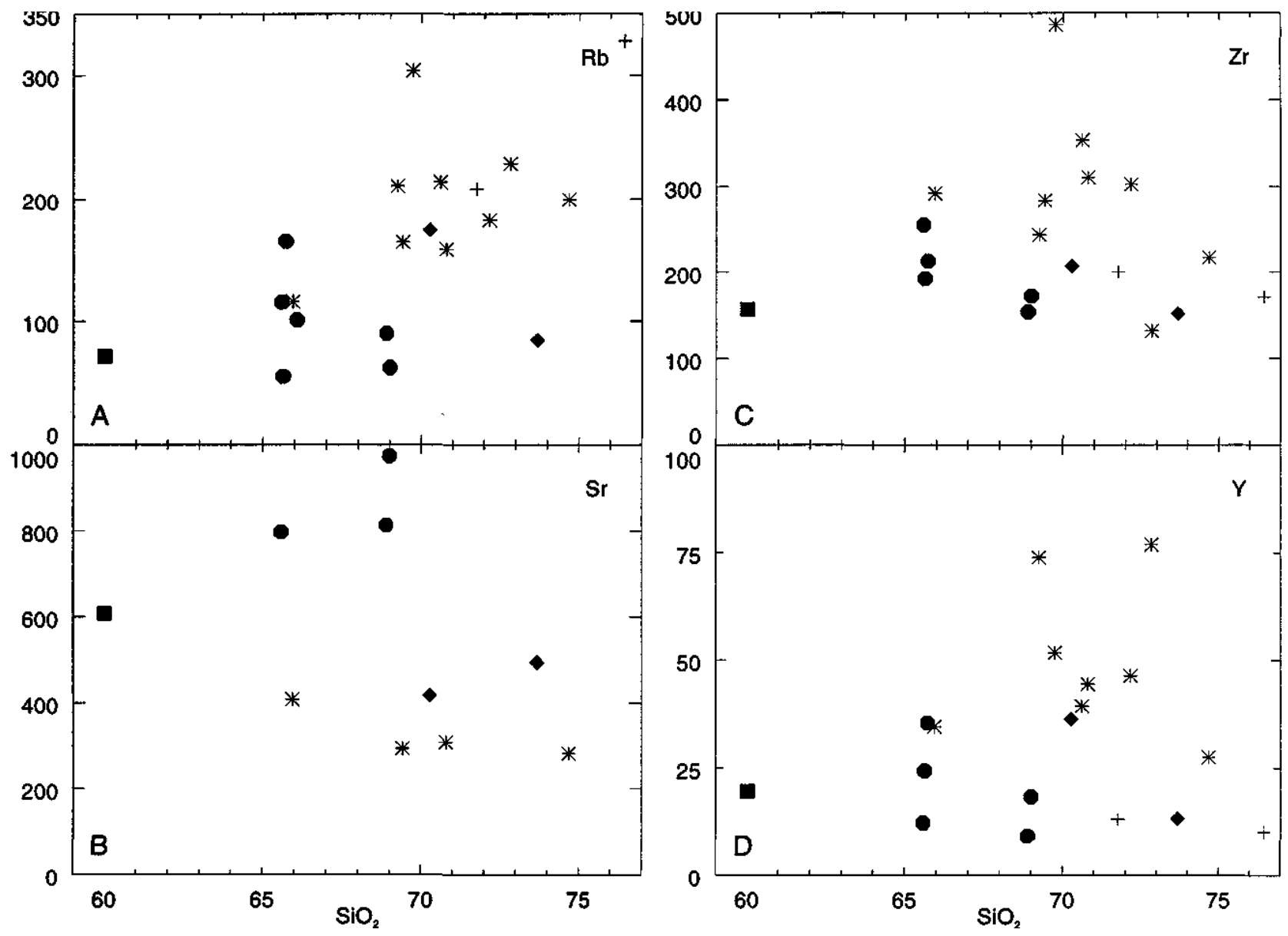

Figura 3 - Diagramas de variação de elementos traços vs. SiO ${ }_{2}$ dos granitóides da Suite Pedra Pintada. Símbolos como na figura 2.

Figure 3 - Trace element vs. $\mathrm{SiO}_{2}$ variation diagrams for granitoids of the Pedra Pintada Suite. Symbols as in figure 2.

As variações observadas para o conjunto dos elementos maiores e menores são ressaltadas no diagrama R1-R2 (La Roche et al 1980; Fig. 4A), onde a distribuição dos granitóides predominantes em duas sequências definidas por composições tonalíticas a (leuco)-granodioríticas para os GND, e composições (leuco)-granodioríticas a graníticas para os $\mathrm{MZG}$, reflete as tendências evolutivas distintas observadas no comportamento do $\mathrm{TiO}_{2}$. As rochas da SIPP definem uma sequência de caráter metaluminoso a marginalmente peraluminoso e de afinidade cálcio-alcalina, onde os granitóides ocupam dominantemente o campo das suítes cálcio-alcalinas de arcos magmáticos modernos, conforme os limites sugeridos por Brown (1982; Fig. 4B). Esta afinidade também é ressaltada no diagrama AFM de Irvine \& Baragar (1971; Fig. 4C) e, considerando os limites dos campos composicionais de Peccerillo \& Taylor (1976; Fig. 4D), os granitóides da SIPP distribuem-se predominantemente no campo da série cálcioalcalina de alto-K.

As rochas da suíte apresentam padrões geralmente fracionados de elementos terras raras (ETR), com as maiores abundâncias de terras raras totais registradas nos MZG (Tab. 1; Fig. 5). Os padrões fracionados de ETR dos GND, com anomalias negativas de Eu pequenas a ausentes sugerem a participação de hornblenda e/ou clinopiroxênio (Hanson 1980) como fases fracionadas ou residuais dominantes, com menor proporção de plagioclásio, o que é compatível com seus conteúdos mais elevados de Sr. Já as anomalias negati- vas acentuadas de Eu nos MZG assinalam uma participação mais efetiva de plagioclásio no fracionamento. Anomalias negativas de Eu pronunciadas também são típicas dos MGL, que se caracterizam por um acentuado fracionamento de ETRP, o que os aproxima mais dos GND. Por outro lado, o acentuado empobrecimento em ETRM dos SNG indica maior participação de anfibólio como fase fracionada ou residual, acompanhado ou não por plagioclásio. conforme sugerido pelas anomalias positiva e negativa de $\mathrm{Eu}$.

O comportamento dos ETR sugere que a evolução dos magmas parentais dos granitóides Pedra Pintada seria controlada por mecanismos de separação cristal-líquido com as fases potenciais de fracionamento correspondendo a minerais máficos (clinopiroxênio e/ou hornblenda) e feldspatos (plagioclásio \pm feldspato alcalino). A participação de zircão como fase acessória potencial de fracionamento é compatível com o empobrecimento em ETRP dos MGL e, em menor proporção, dos GND, enquanto que um fracionamento mais pronunciado de apatita poderia resultar no enriquecimento relativo de $\mathrm{Eu}$, conforme indica a anomalia positiva de uma amostra dos SNG. Por outro lado, a participação de fases acessórias do tipo ilmenita, titanita e apatita também é sugerida pelas pronunciadas depressões em Ti e P que caracterizam o conjunto dos granitóides nos diagramas de elementos incompatíveis da figura 6.

Os granitóides da SIPP mostram concentrações relativamente elevadas de elementos LIL (K, Rb, Ba, TRL) em 

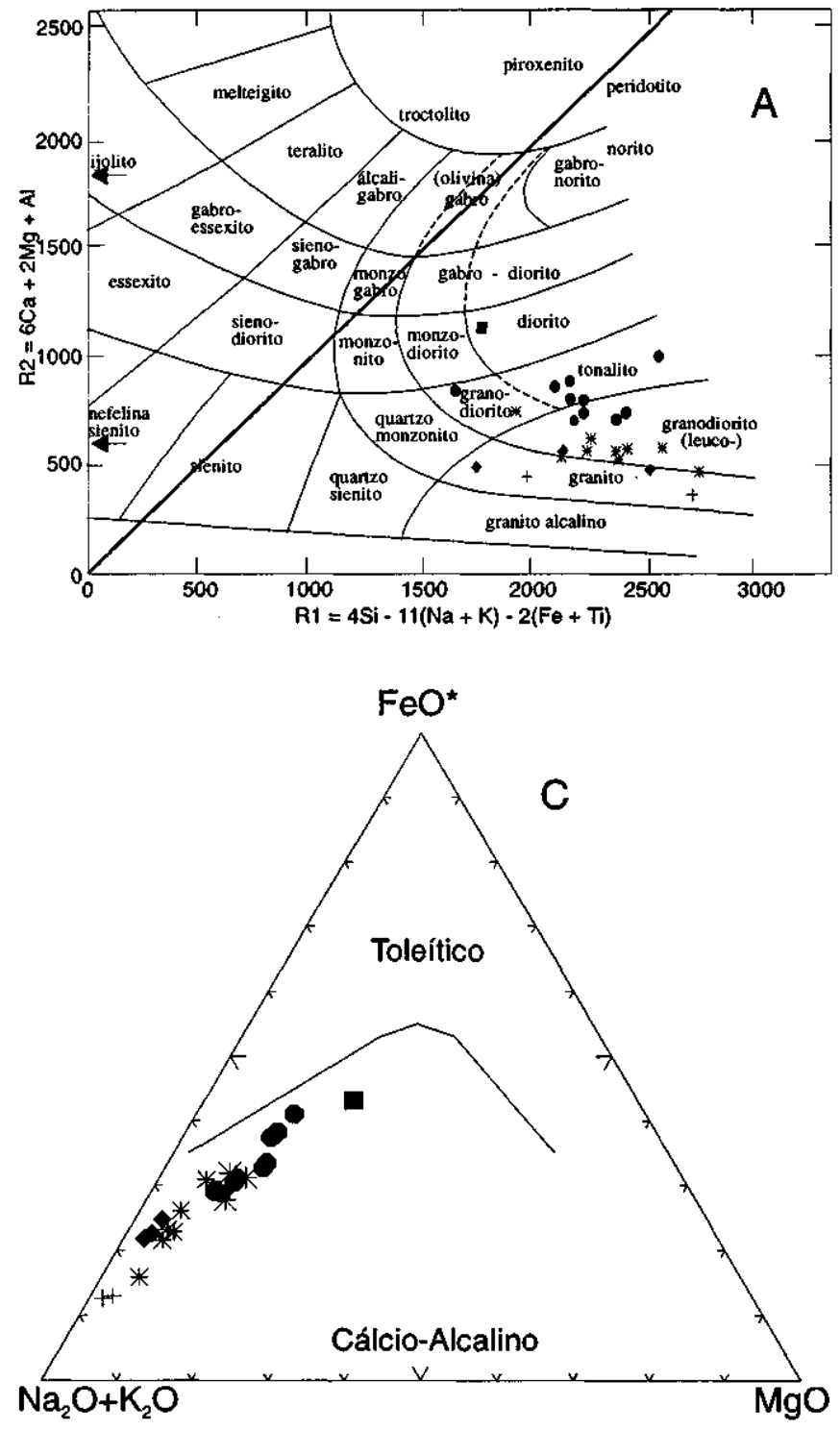
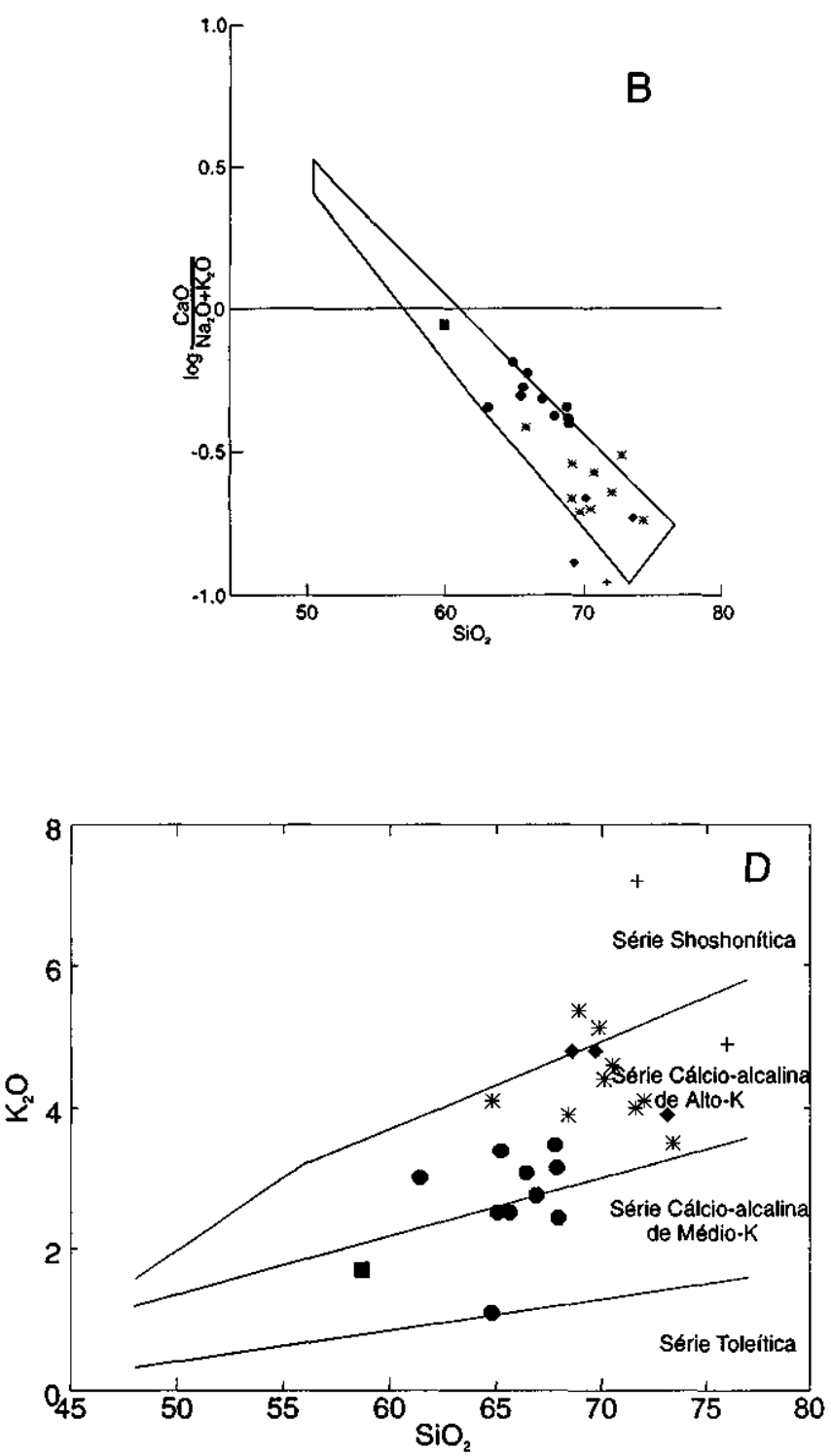

Figura 4 - Distribuição das amostras de granitóides da Suite Pedra Pintada (a) no diagrama R1-R2 de De La Roche et al. (1980), (b) no diagrama $\mathrm{SiO}_{2}$ vs log $\mathrm{CaO} /\left(\mathrm{Na}_{2} \mathrm{O}+\mathrm{K}_{2} \mathrm{O}\right)$ de Brown (1982), (c) no diagrama AFM de Irvine \& Baragar (1971) e (d) no diagrama $\mathrm{K}_{2} \mathrm{O}$ vs $\mathrm{SiO}_{2}$ de Peccerillo \& Taylor (1976). Símbolos como na figura 2.

Figure 4 - Distribution of samples of the Pedra Pintada Suite in the (a) - R1-R2 diagram of La Roche et al. (1980), (b) $\mathrm{SiO}_{2}$ vs $\log \mathrm{CaO} /\left(\mathrm{Na}_{2} \mathrm{O}+\mathrm{K}_{2} \mathrm{O}\right)$ of $\mathrm{Brown}$ (1982), (c) AFM diagram of Irvine \& Baragar (1971), and (d) $\mathrm{K}_{2} \mathrm{O}$ vs $\mathrm{SiO}_{2}$ diagram of Peccerillo \& Taylor (1976). Symbols as in figure 2.

relação a elementos HFS (Nb, Ti), apresentando depressões bem definidas para $\mathrm{Nb}$ (mais pronunciadas nos GND e MGL), típicas de granitóides cálcio-alcalinos (Thompson et al 1984). O empobrecimento em $\mathrm{Nb}$ é acompanhado por depressões em P e Ti, mais desenvolvidas nos MZG e MGL, onde são características anomalias negativas acentuadas em Sr. Estas feições são similares àquelas observadas em magmas enriquecidos em LILE por processos ligados à subducção, em arcos magmáticos modernos ou intrusões cálcioalcalinas pós-colisionais. $\mathrm{O}$ aumento relativo nos teores de $\mathrm{Y}$ dos MZG e MGL é sugestivo de rochas geradas com um componente de manto intraplaca (Brown et al 1984).

CONSIDERAÇÕES FINAIS A tendência cálcioalcalina e o enriquecimento em elementos LIL em relação aos
HFS são características sugestivas da participação de fontes mantélicas com assinatura de subducção na génese dos magmas parentais dos granitóides da SIPP, envolvendo a contribuição, em maior ou menor proporção, de componentes de manto intraplaca e material crustal. $\mathrm{O}$ intervalo composicional restrito que caracteriza estas rochas, com sílica entre $64,70 \%$ e $76,00 \%$ contrasta, no entanto, com as suítes expandidas dos arcos magmáticos tipicamente cálcio-alcalinos. Por outro lado, em diagramas discriminantes para ambientes tectônicos (Fig. 7), as rochas da SIPP distribuem-se próximo às intersecções dos campos dos granitos de arco magmático, granitos sin-colisionais e granitos intraplaca, denotando um comportamento que, segundo Pearce et al. (1984) e Harris et al. (1986) é observado em suítes geradas em zonas de colisão continental, durante o soerguimento pós-colisional. 

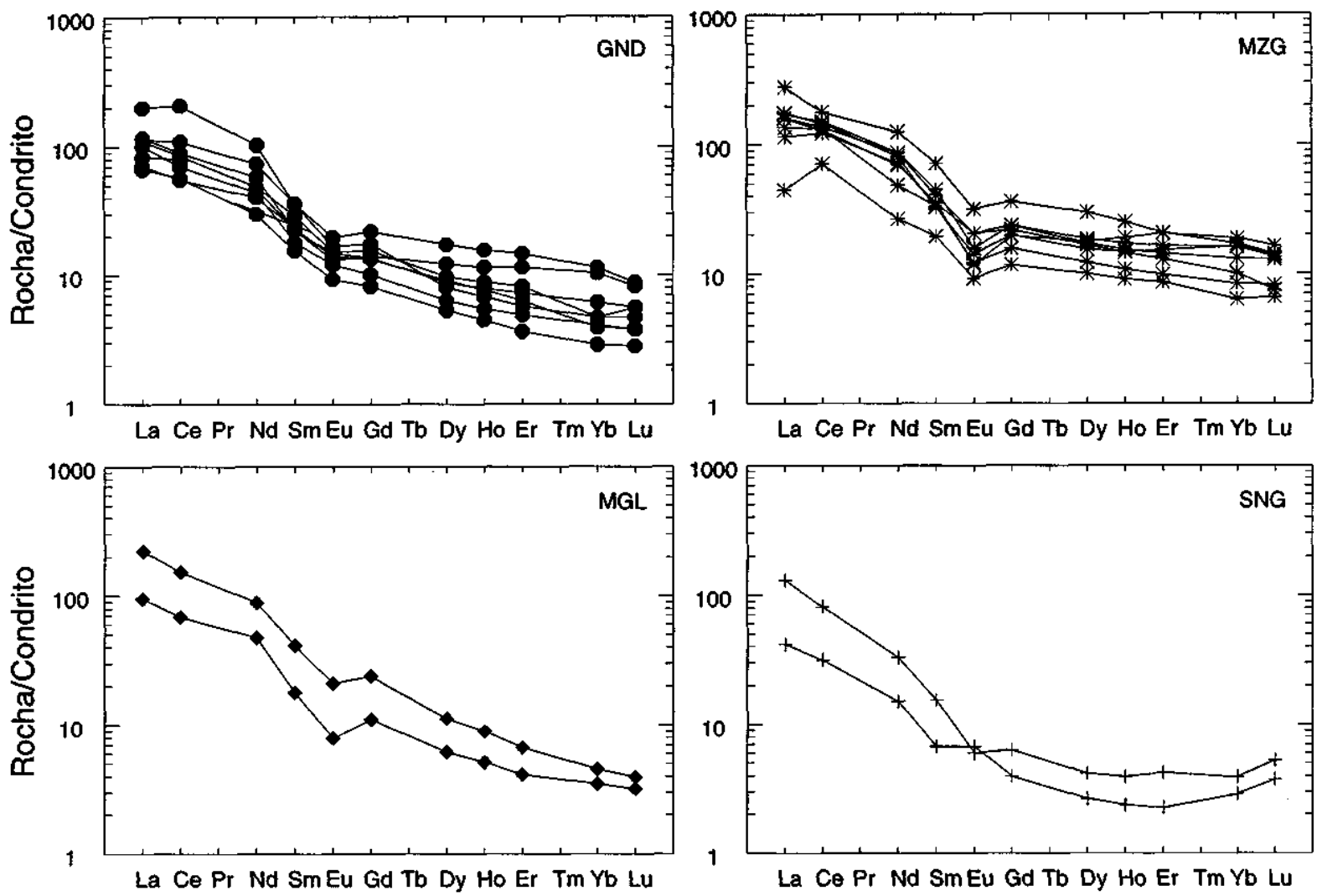

Figura 5 - Padrões de ETR dos granitóides da Suite Pedra Pintada, normalizados ao condrito de Boynton (1984).

Figure 5 - Chondrite-normalized REE patterns of the Pedra Pintada Suite granitoids. Normalization values after Boynton (1984).
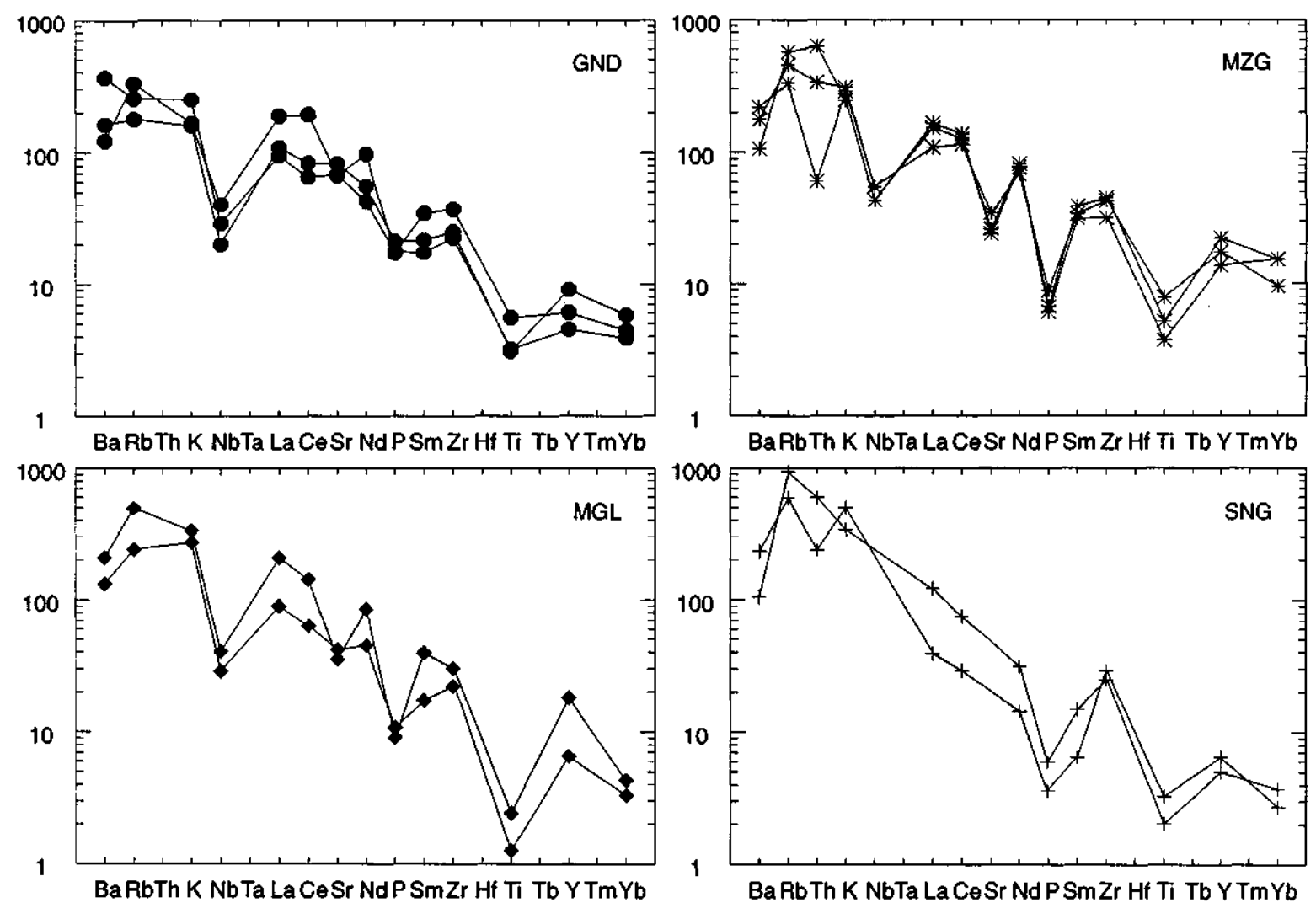

Figura 6 - Padrões de elementos incompativeis dos granitóides da Suite Pedra Pintada, normalizados pelos valores condríticos de Thompson et al. (J984).

Figure 6 - Chondrite-normalized spiderdiagrams of the Pedra Pintada Suite granitoids. Normalization values after Thompson et al. (1984). 


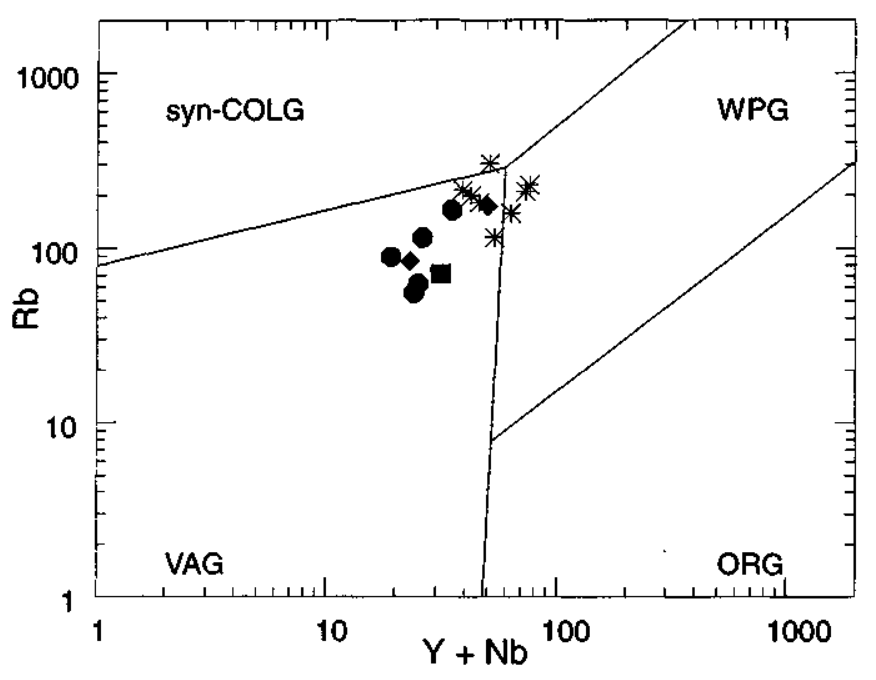

Figura 7 - Distribuição dos granitóides da Suite Pedra Pintada no diagrama $R b$ vs $Y+N b$ para discriminação tectônica de granitos de Pearce et al. (1984). V AG: granitos de arcos vulcânicos; ORG: granitos de cadeias oceânicas; synCOLG: granitos sin-colisionais; WPG: granitos intra-placa. Símbolos como na figura 2.

Figure $7-\mathrm{Rb}$ vs $\mathrm{Y}+\mathrm{Nb}$ tectonomagmatic discrimination diagram of Pearce et al. (1984), for granitoids of the Pedra Pintada Suite: VAG = volcanic ares granites; $\mathrm{ORG}=$ ocean ridge granites; syn-COLG $=$ syn-collision granites; $\mathrm{WPG}=$ within plate granites. Symbols as in figure 2.
As variações observadas nos granitóides da Suíte Intrusiva Pedra Pintada indicam que os diferentes grupos químicos que caracterizam esta associação não definem uma tendência evolutiva única, sugerindo a presença de pulsos magmáticos distintos, que devem refletir contribuição de rochas-fontes e/ou processos evolutivos levemente diferenciados, apesar de relacionados ao mesmo ambiente geotectônico.

As similaridades químicas observadas por Reis \& Fraga (1996) entre os granitóides da SIPP e os vulcanitos do Grupo Surumu (até então considerado como a fase extrusiva relacionada aos granitos da Suíte Intrusiva Saracura) apontam para uma relação de cogeneticidade entre estas duas unidades, o que, aliado às idades próximas, é sugestivo de um ambiente geotectônico único para o plutonismo e vulcanismo cálcio-alcalino nesta porção do Escudo das Guianas.

O Ciclo Transamazônico tem sido interpretado no Escudo das Guianas como relacionado à evolução de arcos magmáticos. a partir de subducção de crosta oceânica com acreção crustal, e posterior colisão (Teixeira et al. 1989; Gibbs \& Barron 1993; Ledru et al. 1994). A possibilidade de atuação de processos colisionais também foi levantada por Hasui et al. (1984). O quadro geológico evolutivo para a porção brasileira do Escudo das Guianas é ainda obscuro, em especial quanto ao significado geotectônico do Ciclo Transamazônico. De qualquer forma, as características químicas observadas, aliadas ao posicionamento temporal dos granitóides da SIPP no final do Ciclo Transamazônico. são compatíveis com a sugestão de um ambiente pós-colisional.

\section{REFERÊNCIAS}

ALMEIDA M. E. FRAGA, L. M. B. \& MACAMBIRA M. J. B. 1997. New geochronological data of calk-alkaline granitoids of Roraima State, Brazil. In: SOUTH-AMERICAN SYMPOSIUM ON ISOTOPE GEOLOGY, Campos de Jordão, 1997. Extended Abstracts... Campos do Jordão, SP. p. 34-35.

ARAÚJO NETO, H. \& MOREIRA, H.L. 1976. Projeto Estanho do Abonarí. Relatório Final. Manaus, DNPM/CPRM, Relatório Inédito, $2 \mathrm{v}$.

BOYNTON, W.V. 1984. Cosmochemistry of the rare-earth elements: meteorite studies. In: HENDERSON, P. ed. Rare-earth Elements Geochemistry. Amsterdam, Elsevier. p. 63-114.

BROWN, G.C. 1982. Calc-alkalineintrusiverocks: theirdiversity, evolution, and relation to volcanic ares. In: THORPE, R.S. ed. Orogenic Andesites and Related Rocks. London, John Wiley \& Sons. p. 437-461.

BROWN, G.C.; THORPE, R.S. \& WEBB, P.C. 1984. The geochemical characteristics of granitoids in contrasting ares and comments on magma sources. Journal of the Geological Society of London, 141:413426 .

DALL'AGNOL, R.; BETTENCOURT, J.S.; JORGE JOÃO, X.S.; MEDEIROS, H.; COSTI, H.T. \& MACAMBIRA, M.J.B. 1987. Granitogenesis in northern Brazilian region: a review. Revista Brasileira de Geociências, 17(4):382-403.

DALL'AGNOL, R.; LAFON, J.M. \& MACAMBIRA, M.J.B. 1994. Proterozoic anorogenic magmatism in the Central Amazonian Province, Amazonian Craton: geochronological, petrological and geochemical aspects. Mineralogy and Petrology 50:113-138.

DUTRA, C.V. \& GOMES, C.B. 1984. A fluorescência de Raios-X na geologia. In: GOMES, C.B. cd. Técnicas Analiticas Experimentai Aplicadas à Geologia.. Edgard Blücher Ltda, São Paulo, p. 84-120.

FRAGA, L.M.B. \& REIS, N.J. 1995. The rapakivi granite - anorthosite association of Mucajaí region - Roraima State, Brazil. In: SIMPOSIUM ON RAPAKIVI GRANITES AND RELATED ROCKS, 1 Belém, 1995. Anais ... Belém, IUGS/UNESCO/IGCP. Bol Res. Exp.:31-32.

FRAGA, L.M.B.; REIS, N.J. \& PINHEIRO, S.S. 1994. Arranjo estrutural do segmento sul do Bloco Pacaraima - Estado de Roraima. In: SIMP GEOL AMAZÓNIA, 4, Belém, 1994. Anais... Belém, SBG/NO. Bol. Res. Exp.:31-32.

FRAGA, L.M.B.; REIS, N.J.; ARAÚJO, R.V.; \& HADDAD, R.C. 1996. Suíte Intrusiva Pedra Pintada - um registro do magmatismo pós-colisional no Estado de Roraima. In: SIMP. GEOL. AMAZÓNIA, 5, Belém, 1996. Anais... Belém, SBG/NO. Bol. Res. Exp.:76-78
GIBBS, A.K. \& BARRON, C.N. 1993. The geology of the Guiana Shield. Oxford Monographs on Geology and Geophysics. New York, Oxford University Press, Clarendon Press, $246 \mathrm{p}$.

HANSON, G.N. 1980. Rare earth elements in petrogenetic studies of igneous systems. Annual Reviews of Earth and Planetary Science, 8:371-406.

HARRIS, N.B.W.; PEARCE, J.A. \& TINDLE, A.G. 1986. Geochemical characteristics of collision-zone magmatism. In: COWARD, M.P. \& RIES, A.C. eds. Collision Tectonics. Geological Society Special Publication, 19:67-81.

HASUI, Y.; HARALYI, N.L. \& SCHOBBENHAUS, C. 1984. Elementos geofísicos e geológicos da região Amazônica: subsídios para o modelo geotectônico. In: SIMPOSIUM AMAZÔNICO, II, Manaus, 1984 Anais... Manaus, MME/DNPM. p. 129-147.

IRVINE, T.N. \& BARAGAR, W.R.A. 1971. A guide to the chemical classification of the common volcanic rocks. Canadian Journal of Earth Sciences, 8:523-548.

JORGE JOÃO, X.S.; SANTOS, C.A. \& PROVOST, A. 1985. Magmatismo adamelítico Água Branca (Folha Rio Mapuera, NW do Estado do Pará). In: SIMP. GEOL. AMAZONIA, 2, Belém, 1985. Anais... Belém, SBG/NO. v.2, p. 93-109.

LA ROCHE, H. De; LETERRIER. J.; GRANDCLAUD, P. \& MARCHAL M. 1980. A classification of volcanic and plutonic rocks using R1-R2 diagrams and major elements analysis - its relationships with current nomenclature. Chemical Geology, 29:183-210.

LEDRU, P.; JOHAN, V.; MILÉSI, J.P. \& TEGYEY, M. 1994. Markers of the last stages of the Paleoproterozoic collision: evidence for a $2.0 \mathrm{Ga}$ continent involving circum-South Atlantic provinces. Precambrian Research, 69:169-191.

MELO, A.F.F.; SANTOS, A.J.; CUNHA, M.T.P.; CAMPOS, MJ. \& D'ANTONA, R.J.G. 1978. Projeto Molibdênio em Roraima. Relatório Final Manaus, DNPM/CPRM, v. 1A, 316p.; v.1B, 500p.

OLIVEIRA, M.J.R.; LUZARDO, R.; FARIA, M.S.G. \& PINHEIRO, S.S 1996a. A Suíte Intrusiva Água Branca no sudeste do Estado de Roraima. In: SIMP. GEOL. AMAZÓNIA, 5, Belém, SBG/NO. Bol. Res. Exp.:86-89.

OLIVEIRA, M.J. R.; ALMEIDA, M.E.; LUZARTX). R. \& FARIA, M.S.G 1996b. Litogeoquímica da Suíte Intrusiva Agua Branca - SE de Roraima. In: CONGR. BRÁS. GEOL., 39, Salvador, 1996. Anais... Salvador, SBG/BA. v.2, p. 213-216.

PEARCE, J.; HARRIS, N. \& TINDLE, A. 1984. Trace element discrimination diagrams for the tectonic interpretation of granitic rocks. Journal of Petrology 25:956-983. 
PECCERILLO, A. \& TAYLOR, S.R. 1976. Geochemistry of Eoceno calcalkaline volcanic rocks from the Kastamoru area, Northern Turkey. Contributions to Mineralogy and Petrology, 58:63-81.

REIS, N.J. \& FRAGA, L.M.B. 1995. Granitogênese mesoproterozóica da porção central do Estado de Roraima - Petrologia e Litogeoquímica. In: CONGRESSO LATINOAMERICANO DE GEOLOGIA, 9, Caracas, 1995. Ternário... Caracas, Venezuela, 7p.

REIS, N.J. \& FRAGA, L.M.B. 1996. Vulcanismo Surumu - Estado de Roraima: Caracterização de sẹu comportamento químico à luz de novos dados. In: CONGR. BRÁS. GEOL., 39, Salvador, 1996.Anais.. Salvador, BA, SBG, v. 2 , p. 88-91.

SANTOS, J.O.S. \& REIS NETO, J. M. 1982 Algumas idades de rochas graníticas do Cráton Amazônico. In: CONGR. BRÁS. GEOL., 32 Salvador, 1982. Anais... Salvador, SBG/BA. v.1, p. 339-348.

SCHOBBENHAUS, C.; HOPPE, A.; LORK, A. \& BAUMANN, A.1994 Idade $\mathrm{U} / \mathrm{Pb}$ do magmatismo Uatumã no norte do Cráton Amazônico, Escudo das Guianas (Brasil): primeiros resultados. In:CONGR. BRÁS. GEOL.,38, Camboriú, 1994. Anais... Camboriú, SBG/SC. v.2, p.395397.

TEIXEIRA, W; TASSINARI, C.C.G.; CORDANI, U. \& KAWASHITA, K. A review of the Amazonian Cráton: Tectonic Implications. Precambrian Research, 42:213-227.
THOMPSON, R.N.; MORRINSON, M.A.; HENDRY, G.L. \& PARRY, S.J. 1984 An assessment of the relative roles of crust and mantle in magma génesis: an dementai approach. Philosophycal Transactions of the Royal Society of London, 310(A):549-590.

TRESCASES, J.J. 1984. Análise química por espectrometria de absorção atómica. In: GOMES, C.B. cd. Técnicas Analiticas Experimentais Aplicadas à Geologia. Edgard Blücher Ltda, São Paulo, p. 44-83.

VEIGA JR, J.P.; NUNES, A.C.B.; SOUZA, E.C.; SANTOS, J.O.S.; AMARAL, J.E.; PESSOA, M.R. \& SOUZA, S.A.S. 1979. Projeto Sulfetos do Uatumã. Relatório final. Manaus, DNPM/CPRM, v. 1 A, 207p.; v.lB, 519p.

VERNON, R.H.; ETHERIDGE, M.A. \& WALL, V.J. 1988. Shape and microstructure of microgranitoid enclaves: indicators of magma mingling and flow. Lithos, 22:1-11.

Manuscrito A873

Recebido em 15 de novembro de 1996

Revisão dos autores em 15 de abril de 1997

Revisão aceita em 15 de junho de 1997 